\title{
DISCURSOS FRANCESES SOBRE LA REVUELTA CATALANA Y LA SOBERANÍA DE LOS REYES DE FRANCIA SOBRE CATALUÑA
}

\author{
FRENCH DISCOURSES ON THE CATALAN REVOLT AND THE \\ SOVEREIGNTY OF THE KINGS OF FRANCE OVER CATALONIA
}

\author{
Matthias GloËL \\ Universidad Católica de Temuco \\ Montt 56, Temuco, Chile \\ mgloel@uct.cl
}

\begin{abstract}
RESUMEN
Este artículo analiza los distintos discursos que hubo en Francia en la década de 1640 acerca de la revuelta catalana. El análisis se divide en tres secciones: primero, las publicaciones sobre la revuelta propiamente tal, segundo, aquellas acerca del cambio dinástico de Felipe IV a Luis XIII de Francia y tercero, las justificaciones de los derechos dinásticos históricos de la corona francesa sobre Cataluña. Se toman en cuenta tanto traducciones de obras catalanas como escritas por autores franceses. El objetivo es evidenciar la diversidad de discursos que existían para justificar el dominio de la corona francesa sobre Cataluña
\end{abstract}

Palabras clave: revuelta catalana, discursos franceses, cambio dinástico, derechos históricos sobre Cataluña. 


\begin{abstract}
This article analyzes discourses in France in the decade of 1640 about the Catalan revolt. The analysis is divided into three sections: first, publications about the revolt itself, second, publications about the dynastic change from Philip IV to Louis XIII of France, and third, the justifications of historical dynastic rights of the French crown over Catalonia. We consider translations of Catalan works as well as writings by French authors. The paper shows the existence of a diversity of discourses in order to justify the dominion of the French crown over Catalonia.
\end{abstract}

Keywords: Catalan Revolt, French Discourses, Dynastic Change, Historical Rights over Catalonia.

Recibido: 03/03/2021

Aceptado: 16/06/2021

\title{
I. INTRODUCCIÓN
}

Durante los años de 1641 a 1652, Luis XIII y Luis XIV de Francia fueron condes de Barcelona como consecuencia de la revuelta estallada a mediados de 1640, conocida también como la Guerra de los Segadores. La revuelta, a su vez, fue de cierta forma la culminación de un largo proceso de desentendimiento entre la corona y el principado. Ernest Belenguer (68-9) ubica los inicios de estas discrepancias en la década de 1530, aunque matiza que las relaciones no indicaban en una línea recta de decrecimiento, ya que hubo episodios como las cortes de 1585 que fueron bastante favorables para Cataluña. En general, sin embargo, el reinado de Felipe II (1556-1598) estuvo marcado ya por una serie de conflictos institucionales (Pérez Latre 113-180). También el reinado de Felipe III (1598-1621) conllevaría una serie de decepciones, empezando por el hecho de celebrarse el matrimonio del rey en Valencia y no en Barcelona (Chamorro Esteban 78). El reinado de Felipe IV sería más bien peor, empezando por los problemas de confirmar a los primeros virreyes por no haber jurado todavía las constituciones hasta las fallidas cortes de 1626 y 1632 (Elliott 215-305). 
Finalmente, la guerra entre las monarquías española y francesa, en el contexto de la Guerra de los Treinta Años, llevaría al alojamiento de los soldados de Felipe IV en las casas particulares de los catalanes, lo que sería clave para el estallido de la revuelta de 1640. La revuelta terminó con el cambio dinástico en enero de 1641. Primero, el 16 de aquel mes, el principado le quitó la jurisdicción y la obediencia a Felipe IV. Una semana después también la soberanía cuando Luis XIII de Francia se convirtió en conde de Barcelona. Como ha demostrado Daniel Aznar ("¿Llorar de amor...?" 289-300), la durante mucho tiempo asumida primera república catalana nunca se proclamó, ya que la monarquía no fue abolida en ningún momento.

Varios autores franceses trataron de legitimar la revuelta catalana, por una parte, y la soberanía de dichos monarcas sobre el principado, por otra. La historiografía se ha ocupado de estas obras habitualmente solo de forma lateral en el contexto de autores catalanes que publicaban para este mismo fin (Simon i Tarrés, Els origens...; Simon i Tarrés, Construccions...; Torres Sans; Neumann; Pelayo y Jiménez Sureda; Villanueva, Política...). Por su parte, Carlos Terrón Vasco ha estudiado la presencia de Francia en algunos sermones catalanes de esos ańos que refieren a los acontecimientos políticos del momento.

En cuanto a los escritos historiográficos y de poder político, solamente Jesús Villanueva ("Intentos franceses... ") dedica un breve estudio enfocado en las legitimaciones francesas, que trata la publicística junto con la actuación política de los cardenales Richelieu y Mazarino. Si bien dicho estudio es muy valioso, por el corto espacio que dispone no entra en demasiados detalles en cuanto a la retórica y la argumentación de las obras francesas. Además, Villanueva excluye de su estudio la obra de Pierre de Marca, Marca Hispanica, que se publicó en 1688 y fuera escrita entre 1644 y 1651 (Simon i Tarrés, Els origens... 271), debido, probablemente, al hecho de que Villanueva asume que la obra de Marca habría sido más bien o en mayor parte obra de Étienne Baluze (1630-1718), historiador que publicó la Marca Hispanica de forma póstuma en 1688 (Villanueva, "La Marca Hispanica... "206-7). Marca escribió el texto cuando fue visitador real en Cataluña, tiempo en que sería clave para el cese del virrey La Mothe y el nombramiento de su 
sucesor, el conde de Harcourt (Aznar, "La Catalunya borbònica” 369-270). Según Villanueva, durante la administración francesa en Cataluña, Marca solo escribió los libros dos y tres (de hecho, al inicio del capítulo cuatro dice "Auctore Stephano Baluzio Tutelensi”), que por lo tanto serán los únicos que ocuparemos en este estudio. Las otros estudios esenciales para nuestro análisis son los siguientes:

- La deffence des Catalans (1642) de Charles Sorel, quien fue autor de una multitud de obras, pero que ha sido destacado principalmente por sus escritos literarios. Pero llegó a ser historiógrafo real y protegido de Richelieu durante la totalidad de su gobierno (Aznar, Cataluña y el rey 40).

- La Catalogne Françoise (1644) de Pierre Caseneuve, un erudito de la primera mitad del siglo XVII quien principalmente publicó tratados de historia regional sobre el Languedoc de donde era oriundo. La obra ya estaba escrita en 1642 , pero no se pudo publicar hasta 1644 , posiblemente por reparos de Richelieu que prefería el discurso más suave de Sorel frente a la exposición más radical de Caseneuve (Aznar, Cataluña y el rey 473-4).

- Catalania Galliae Vindicata (1644) de Louis Mesplède, Tanto la obra como su autor, un padre dominico, son muy poco conocidos.

- Como antecedentes importantes de estas obras se encuentran los escritos de Pierre Dupuy y Théodore Godefroy (publicados en 1655, pero escritos a lo largo del gobierno de Richelieu), ambos historiadores, y Jacques de Cassan, abogado del rey (1634).

Lo que no se ha tenido en cuenta hasta ahora son las traducciones al francés de obras catalanas de aquellos años. Su importancia radica en la incorporación de los discursos catalanes entran en el debate erudito francés, ya que se replican en aquella lengua los argumentos empleados en Cataluña. Nos referimos en este contexto a la Plainte Catholique des Catalans (1642), traducción de la Proclamación católica (1640) de Gaspar Sala (Serra) y la recopilación Histoire de tout ce qui sest passé en la Catalogne (1642) que 
incluye traducciones de tres obras de Gaspar Sala: Apoyos a la verdad catalana (1640), Secrets Públics (1640) y Epitome de los principios y progresos de la Guerra de Cataluña en los años 1640 y 1641 y señalada victoria de Monjuyque (1641). No se conoce el traductor, pero parece probable que sea solo una persona que tradujo las tres obras de Sala, para que las publicara en esta recopilación Jean Berthlin (1577-1652), un impresor de Ruan que inició un linaje familiar de impresores en aquella ciudad (Lesens).

Sala fue un teólogo aragonés de nacimiento, pero casi toda su vida adulta estuvo vinculado a Cataluña. Se convertiría también en historiador e incluso, después de la Paz de los Pirineos (1659), en cronista oficial del rey de Francia. Como se desprende de los tres títulos originales, un texto se publicó en catalán, mientras los otros dos se escribieron en castellano, lo que indica que los Secrets Públics (si bien se hizo una traducción castellana) se redactaron para un público catalán y extenso, ya que fuera de las élites pocos dominaban el castellano (Peña Díaz). Los textos en castellano, en cambio, aspirarían a una difusión más amplia a nivel europeo. Secrets Públics y el Epitome tuvieron, además, traducciones al portugués, lo que evidencia que en el contexto de la rebelión portuguesa también se usaban textos catalanes para un amplio uso propagandístico interno, ya que las élites portuguesas dominaban el castellano, al igual que las catalanas (Gloël y Vivar). El Apoyo a la verdad catalana se publica de forma bilingüe, no hay certeza acerca del motivo de este hecho.

El objetivo de este artículo es evidenciar la diversidad de justificaciones que había en los discursos franceses para legitimar el dominio de la corona francesa sobre Cataluña. Por ello, dividimos el análisis en tres bloques: la justificación de la revuelta catalana, la justificación del cambio dinástico de Felipe IV a Luis XIII y la defensa de una soberanía histórica de la corona francesa sobre Cataluña. 


\section{JUSTIFICACIONES DE LA REVUELTA}

Como es sabido, la Proclamación Católica de Gaspar Sala se inscribe en un primer momento de la revuelta catalana, cuando aún no había una contradicción respecto de la fidelidad a la dinastía de Felipe IV (III en Cataluńa). Por ello, dicha obra se dirige en su portada "a la Magestad piadosa de Felipe el Grande, Rey de las Españas u Emperador de las Indias, Nuestro Señor". Esta obra se difundió activamente desde Barcelona a otros reinos europeos para justificar lo ocurrido. De hecho, en la portada de la traducción francesa se señala que fue "traduit d'Espagnol en François, sur la Coppie envoyée de Barcelone"1. Ahora bien, esta postura fidelista a los Habsburgo había quedado obsoleta cuando se publicó la traducción, ya que el 16 de enero de 1641, el principado revocó la obediencia a Felipe IV y el 23 de enero Luis XIII de Francia fue jurado como conde de Barcelona. Sala culpa a los ministros del rey de haber propiciado la destrucción del principado y contrapone sus vicios a las virtudes de los catalanes, que mostrarían fidelidad al rey en su religiosidad y en el ámbito militar.

Como han evidenciado distintos estudios, era común en aquella época no traducir fielmente sino adaptar las traducciones a los intereses propios (Nida 226-38; Catford 63). Sin embargo, la Plainte Catholique destaca por su fidelidad al original, que se ve plenamente representado en la versión francesa. Eso incluye las apelaciones finales dirigidas a Felipe IV para que cambie de gobierno y para que se vuelva a la paz entre el rey y el principado (Sala, Plainte Catholique 137-8). Incluso se traduce una referencia a la fidelidad catalana en un momento en que ayudaban a su rey contra "l'usurpation des Comtez de Roussillon \& de Sardagne"2 por parte del monarca francés (9).

Por lo tanto, al igual que en el original, las acusaciones concretas se dirigen fundamentalmente contra los soldados del rey, instalados en

\footnotetext{
1 "traducido del español al francés, a partir de la copia enviada de Barcelona”. Todas las traducciones son mías, excepto que se indique lo contrario.

2 "la usurpación de los condados de Rosellón y de Cerdeña".
} 
Cataluña por la guerra con la monarquía francesa desde 1635. En varios capítulos, se describe lo que en una parte determinada del texto es definido como "la tyrannie des soldats"3 contra la población del principado (68).

El mismo Gaspar Sala retoma la caracterización de la tiranía de los soldados en los Secrets Públics, obra publicada en 1640 y traducida al francés en 1642. Como en el caso anterior cabe destacar la fidelidad de la traducción al original, por lo que nuevamente podemos afirmar que se hacía accesible al público francés la argumentación catalana. El texto consiste en rebatir un escrito contrario al levantamiento catalán, en defensa del gobierno olivarista. Este método era bastante habitual en aquella época, especialmente en el contexto de revueltas como la catalana o la portuguesa. El hecho de que el original está escrito en catalán indica que estaba dirigido principalmente a los propios catalanes, por lo que también este discurso interno del principado se ofrece al público francés.

A diferencia de la Proclamación, dirigida más bien contra el gobierno de Olivares, los Secrets Publiques de la Catalogne identifican como enemigo principal a los castellanos. En este sentido, Sala (Secrets Publiques 17-22) refiere a "les tyrannies \& les inhumanitez de ces soldats Castillans" además las acciones cometidas en Cataluña con las ocurridas en las Indias, para ello cita a Bartolomé de las Casas. En la conclusión, además compara el yugo castellano con el de los musulmanes y argumenta que Cataluña habría cambiado una dominación por la otra (42). Lo anterior es preciso leerlo también en clave religiosa, ya que se mantiene la oposición de los buenos católicos catalanes y los que actúan en contra de la fe y de los sacramentos, sean moros o castellanos.

La misma estructura de los Secrets Publiques la tiene también el Appuy de la verité catalane, también "traduite fidellement en François" como anuncia correctamente la portada. Se trata de una versión bilingüe castellano-francesa (1642) de los Apoyos a la verdad catalana de 1640. Retoma argumentos de

\footnotetext{
3 "la tiranía de los soldados".

"las tiranías e inhumanidades de estos soldados castellanos".

"traducido fielmente al francés".
} 
un "libelle imprimé à Madrid, est venu à Barcelone" (Anónimo 3). El texto recorre desde los hechos previos al estallido de la revuelta, empezando con la violación de los derechos del diputado Tamarit y de toda la Generalitat de Cataluña (5-7). A esto se suma el ya conocido hecho de la población violentada por las "violences \& vexations des soldats" calificado como tiranía (23 y 57).

Estos argumentos para justificar la revuelta están también presentes en la obra La deffence des Catalans (1642) de Charles Sorel, autor que, a pesar de su fecunda obra, ha recibido escasa atención por parte de los estudiosos y principalmente como autor literario (Syrovy; Béchade; Roux). Como señala María Soledad Arredondo, la obra se publica en un momento militar clave, precisamente poco después de la toma de Perpiñán por las tropas francesas en septiembre de 1642. El propósito del autor sería atraer a los muchos catalanes todavía indecisos en cuanto a su lealtad, a la causa francesa (Arredondo 213).

La obra de Sorel se ha vinculado en alguna ocasión con la ya citada Proclamación Católica, de hecho, el propio Sorel la menciona en su prólogo ("L’on a desia veu leur Plainte ou Manifieste") (Sorel s/n). Simon i Tarrés (Els origens... 270) resalta el enfoque de la obra sobre "l'opressió espanyola a Catalunya, i d'acord amb el discurs de la Proclamación Católica" . Jesús Villanueva incluso la califica como una "traducción (apenas confesada) de la Proclamación Católica de Gaspar Sala, aunque adaptada al gusto del lector francés" (Intentos franceses... 141). Efectivamente, la primera parte -que expone los acontecimientos alrededor de la revuelta de 1640- parece extraída de la obra de Sala. Sin embargo, para lo que sigue, ya no se puede mantener esta misma afirmación, ya que buena parte de la Deffence des Catalans se aleja bastante de la obra de Sala, entre otros motivos debido al desarrollo de los acontecimientos de 1640 a 1642 . La segunda parte

\footnotetext{
"papel impreso en Madrid, llegó a Barcelona”.

"violencias y vejaciones de los soldados".

"ya se ha visto en su Proclamación o Manifiesto"

"la opresión espańola en Cataluña, y de acuerdo con el discurso de la Proclamación Católica".
} 
de dicha obra se basa en acontecimientos que ocurrieron después de la publicación de la Proclamación Católica, especialmente el cambio dinástico, por lo que resulta lógico el alejamiento de los textos.

Sorel en su prólogo explica que su obra tiene dos propósitos: "non seulement afin de respondre aux calomnies desraisonnables des Espagnols, mais pour apprendre à tous les autres Peuples" ${ }^{10}$. Por hacer conocida su causa, continúa "les Catalans ne seront pas faschez de voir leurs fortunes escrites en langage François" "11, ya que así las otras naciones llegarían a enterarse de los conflictos en Cataluña.

Sorel se suma a las acusaciones hacia los soldados de la monarquía hispánica señalando los sacrilegios y acciones impías cometidos por ellos y las ofensas hacia el santo sacramento. Además, responsabiliza al gobierno de Olivares por la falta de castigo a los culpables y afirma que "il semble mesme que cette impunité ayt autoricé les plus grands crimes"12 (Sorel 45-6).

La revista Mercure Françoise, que se proponía recopilar la historia de Francia, también seńala respecto de la revuelta catalana que bajo la corona de Espańa los catalanes se habrían convertido en esclavos en vez de gozar de sus antiguas libertades (tomo XXIII ${ }^{13}$ 634). Sigue una detallada descripción de los acontecimientos diplomáticos y militares entre Cataluña, la corte de Felipe IV y Francia. En esa misma línea se enfatiza en la malicia de los ministros y en la ignorancia del monarca acerca de la situación en el principado (636). Refiere además al "joug de la tyrannie Espagnole" 14 en general y del Marqués de los Vélez, militar a cargo de la supresión de la revuelta, en particular (663).

\footnotetext{
10 "no solamente para responder a las calumnias irracionales de los Españoles, sino para enseñar a todos los demás pueblos”.

11 "los catalanes no se molestarán por ver sus fortunas escritas en lengua francesa".

12 "parece que esta impunidad ha autorizado los más grandes crímenes".

13 Este tomo abarca desde 1639 a 1640.

14 "yugo de la tiranía espańola".
} 


\section{Justificación del CAMbio dinástico}

Como ya se ha mencionado, en enero de 1641 Cataluña se produce un cambio dinástico en que Felipe IV deja de ser conde de Barcelona y su lugar lo ocupa Luis XIII de Francia. Autores catalanes como Francesc Martí i Viladamor justifican este cambio porque Cataluña sería una monarquía electiva y por la tiranía del gobierno de Felipe IV y sus ministros.

Charles Sorel hace suya esta argumentación en su obra, evidenciando que si bien la primera parte de su texto se pudo inspirar en la Proclamación Católica, después ya no, dado que trata hechos posteriores a la publicación de la obra de Gaspar Sala. Sorel inicia su escrito señalando "le sujet legitime qu'ils [los catalanes] ont eu de se retirer de leur domination [de los espańoles]"15, pues el objetivo declarado del autor es mostrar a todas las naciones que "ce n'est point par un caprice aveugle que la Catalogne a voulu changer de Maistre, \& que cette entreprise n'est point une rebellion, mais la descharge d'un fardeu qu'elle ne pouvoit plus supporter"16 (5).

Más adelante, Sorel se refiere a las constituciones catalanas, es decir, los fueros, que prohibirían el gobierno contra la voluntad de los catalanes. En cambio, la afirmación de que debían ceder a la necesidad de la monarquía y a la voluntad del monarca habría sido inventada solo después de la separación del principado, pero previamente nunca habría sido parte de las obligaciones de los catalanes (Sorel 67-8). La culpa de dicha separación la tendría el propio Felipe IV quien "avoit escrit ou commandé de bouche, beaucoup de choses assez fascheuses" ${ }^{17}$, cosas que Sorel califica de muy impropias de un monarca (85).

Finalmente, Sorel vuelve a destacar expresamente que la legitimidad del cambio dinástico radica en el derecho y en la voluntad del principado,

15 "el objetivo legítimo que han tenido [los catalanes] para deshacerse de su dominio [de los españoles]"

16 "no es por un capricho cegado que la Cataluña ha querido cambiar de señor y que esta empresa no es una rebelión, sino deshacerse de una carga que ella ya no podía soportar más”.

17 "había escrito u ordenado de boca muchas cosas bastante molestosas". 
debido al mal gobierno y justificado en las constituciones, los catalanes "se sont aussi tost soûmis volontairement à celle [la corona] de France"18 (99).

En el Mercure François no se encuentra ninguna alusión directa al cambio dinástico, aunque sí se comentan hechos que son producto de él. Principalmente se trata del envío de virreyes por la corona francesa. Así, se reproduce una carta enviada por Luis XIII al Consell de Cent disculpándose por su ausencia, señalando que, mientras durase, gobernaría en su nombre el Marqués de Brézé. El rey promete, además, que tales medidas asegurarían el cumplimiento de los privilegios y fueros del principado (Mercure Françoise, tomo XXIV 195-6). Sigue reproducida la respuesta del Consell agradeciendo lo anterior y despidiéndose como "fidelissims y obedientissims vassalls" ${ }^{19}$ del rey cristianísimo (197-8).

\section{LOS DERECHOS dinÁsticos de LA CORONA FRANCESA SObre Cataluña}

Las pretensiones históricas de la corona francesa sobre Cataluña no fueron fruto de los acontecimientos de 1640 y 1641, habían sido formuladas ya en las dos décadas anteriores. Aunque se publicó en 1655, fue el cardenal Richelieu quien en 1624 les encargó a Pierre Dupuy y Théodore Godefroy retomar el trabajo de sistematizar los derechos de la corona francesa sobre diversos territorios fuera de Francia. Para ello, se sirvieron del Trésor de Chartes, los antiguos archivos medievales de la corona, lo que era una continuidad de su trabajo desde 1615 y consistía precisamente en ordenar e inventariar dichos documentos, trabajo que llevó a la publicación de dos tratados acerca de usos ceremoniales en Francia (Hanley 270).

El Traitez touchant les droits du Roy tres chrestien sur plusieurs estats et seigneuries possedées par diverses princes voisins postula los derechos del rey de Francia sobre la mayoría de los territorios europeos, incluido el Reino de Inglaterra, diversos estados italianos y la mayoría de los reinos españoles,

\footnotetext{
18 "se han sometido así voluntariamente a la [corona] de Francia".

19 "fidelísimos y muy obedientes vasallos".
} 
entre otros. La base de esos derechos constituye la ley fundamental de la monarquía francesa acerca de la inalienabilidad de territorios en posesión del rey, es decir, el monarca no podría perder nunca ningún territorio una vez que lo ha poseído (Farr Church 365). Tal como lo evidenció Fritz Dickmann, lo anterior era una actitud muy generalizada entre los políticos e intelectuales de la época.

Uno de los capítulos trata de los derechos del rey francés sobre el reino de Aragón o, más bien, la corona de Aragón, ya que dichos derechos incluyen también a Cataluña. Los derechos se remontarían a varios momentos históricos. Por una parte, según los autores habría sido Luis III de Nápoles (Luis de Anjou) el legítimo heredero de la corona en 1410 cuando falleció Martín I sin heredero directo. Dicho Luis estaba casado con Yolanda, hija del rey aragonés Juan I (1387-1396) y sobrina del referido Martín I.

Por ello, refieren Dupuy y Godefroy (161), "les espagnols pour maintenir le droit du Roy d'Espagne au Royaume d'Aragon, \& affoiblir celuy du Roy [de Francia], se sont efforcez en toutes occasions de faire voir que les filles ont esté perpetuellement excluses de la Couronne d'Aragon" ${ }^{20}$. Los autores aluden al caso de la princesa Petronila (1136-1173), hija única del rey Ramiro II quien habría heredado el reino (Dupuy y Godefroy 162). Su matrimonio con Ramón Berenguer IV, conde de Barcelona, además, forjó la unión dinástica entre Cataluña y Aragón. Cabe señalar que en realidad Petronila nunca heredó el reino de Aragón propiamente tal, ya que tras el matrimonio en 1137, el rey Ramiro realiza una donación plena del reino a su yerno Ramón Berenguer (Serrano Daura, "La donación" II). Así quedó asegurado que el reino no se perdería en caso de que Petronila muriera sin descendencia. Ningún documento, además, habla expresamente de derechos sucesorios de la princesa, por lo que en realidad el conde de Barcelona, quien toma el título de príncipe de Aragón, se puede considerar como heredero y no hubo sucesión femenina (Serrano Daura, "El principado" 930).

\footnotetext{
20 "los españoles para mantener el derecho del rey de España sobre el reino de Aragón, y debilitar el del rey [de Francia] se han esforzado siempre en hacer ver que las hijas están perpetuamente excluidas de la corona de Aragón”.
} 
Por otra parte, los autores se refieren al conocido tratado de 1258 entre Jaime II de Aragón y Luis IX de Francia, en el que ambos monarcas reconocieron mutuamente la soberanía del otro. Particularmente, el rey de Francia reconocía los derechos de Jaime como conde de Barcelona sobre el Rosellón y el norte de Cataluña. Dupuy y Godefroy niegan que que el rey de Aragón tuviera derecho a reclamar estos territorios por lo que Luis IX no podía hacer tal reconocimiento. Concluyen, por ello, que "ces droits pretendus par les Rois d'Aragon cedez par cet échange, n'estoient que simples pretentions, la pluspart vaines"21 (Dupuy y Godefroy 167).

En 1634, Jacques de Cassan usa los mismos argumentos para este asunto, aunque no se basa en el tratado de 1258 sino en uno posterior con idéntico contenido. En La recherche des droit du roy, \& de la couronne de France, sur les royaumes, duchez, comtez, villes \& pais occupez par les Princes estrangers, igual como Dupuy y Godefroy, reclama la mayoría de los territorios europeos como patrimonio de la corona francesa, pues, según él, ningún tratado podría revocar "les droicts inalienables de la Couronne" 22 , por lo que los reyes de Francia "ne peuvent avoir esté privez de la Souveraineté, qui leur appartient encore sur a Comté de Catalogne"23 (Cassan 78-80).

Previamente, el autor se refiere a los orígenes de los derechos de la corona francesa sobre Cataluña, que se remontan a tiempos de Carlomagno. De hecho, no se trataría solo del principado, sino también del reino de Aragón, que al ser conquistado "fu uni à la Couronne de France"24 (Cassan 62). El rey franco habría instalado condes en ambos territorios, sin embargo, "sous la foy \& hommage de la Couronne de France"25 (Cassan 64).

Con Cassan también aparece la idea de presentar a los condes de Barcelona como usurpadores, concretamente desde Alfonso II de Aragón

\footnotetext{
21 "los derechos pretendidos por los reyes de Aragón cedidos en este intercambio, no son más que simples pretensiones, en su mayoría vanas".

22 "los derechos inalienables de la corona".

23 "no pueden haber sido privados de la soberanía que les pertenece todavía sobre la corona de Aragón”.

24 "fue unido a la corona de Francia"

25 "bajo el feudo y homenaje de la corona de Francia".
} 
(1164-1196) y Alfonso I en Cataluña (1166-1196). Señala Cassan (73) que hasta aquellas fechas, "tous les Roys d'Aragon, \& Comtez de Catalogne rendirent sans aucun contredit aux Roy de France, la foy $\&$ hommage qu'ils leur devoient pour ce Comte" ${ }^{26}$. Dicho rey Alfonso, en cambio, sería el primero se negó a este acto de vasallaje, con lo cual él y los catalanes estarían cometiendo "un acte de felonnie, de desobeissance \& de rebellion" 27 (76). Con todo, concluye el autor, quedaría comprobado que "la Catalogne est un fief ancien du Royaume de France, duquet il n'a peut estre en aucune façon demembre"28 (88).

Estos discursos se retoman en el contexto del cambio dinástico. Así, Charles Sorel remonta los derechos de la corona francesa a los tiempos de Carlomagno: "Les droict que nos Roys ont sur leur province, sont aussi anciens que Charlemagne"29. Tras la liberación del dominio de los moros el monarca franco habría "establit des Comtes qui devoient relever de la Couronne de France" 30 (Sorel 104-5). Pierre Caseneuve en su Catalogne Françoise (1644) refiere la conquista de Carlomagno y la sujeción de las ciudades de Huesca, Barcelona y Girona y la instalación de condes como gobernadores por parte de los reyes francos (Caseneuve 25 y 33).

Caseneuve contrapone estos derechos originarios -según él los verdaderos- de la corona francesa con el mito de Otger Cataló y los nueve barones, todos nobles francos quienes habrían liberado Cataluña de los moros ya en 735. Esta leyenda que se gestó en la fase final de la Edad Media y que entró en competencia con el mito fundador más antiguo de Wilfredo el Velloso, a quien el rey franco le habría concedido en 875 el dominio hereditario sobre el condado barcelonés (Villanueva, Política y discurso 1921). Casenueve (20) cita a cronistas conocidos como Carbonell, Tomich,

\footnotetext{
26 "todos los reyes de Aragón y condes de Barcelona rindieron sin contradicción alguna al rey de Francia, el feudo y homenaje que este conde les debía". "un acto de felonía, de desobediencia y de rebelión".

"Cataluña es un antiguo feudo del reino de Francia, por lo que no puede ser desmembrada de ninguna manera”.

29 "Los derechos que nuestros reyes tienen sobre su provincia, son tan antiguos como Carlomagno".

30 "establecido condes que debían aumentar la corona de Francia".
} 
Escolano o Siculo como ejemplos de aquellos que habrían difundido lo que el autor califica como "tradition fabuleuse" 31 .

El mismo ańo de la publicación de la obra de Caseneuve, se edita la Catalania Galliae Vindicata de Louis Mesplède, escrita en latín. Como los demás refiere la conquista de Carlomagno y caracteriza a los condes de Barcelona como "Regum nostrorum clientes professi sunt" ${ }^{32}$ (Mesplède 14-7). Rechaza a su vez el traspaso de la soberanía al "Vuifredo fabulam"33 y afirma que el condado se mantenía como un feudo de los reyes francos (19). Más adelante en la obra retoma el tema refiriéndose al autor Marineo

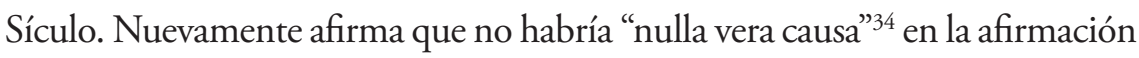
de que el rey franco había renunciado al condado barcelonés "in gratiam Vuifredi" ${ }^{35}$ (92).

También Pierre de Marca en Marca hispanica rechaza los dos mitos fundadores catalanes. Señala al cronista catalán Pere Tomich (muerto en 1481) como iniciador de estas fábulas y al que habría creído después toda España (cita a Beuter, Garibay, Blanca). Repasa el mito de Otger Cataló concluyendo que se trata de una "fabula certa" 36 (242). De forma parecida trata más adelante la "fabula de Vuifredo", también muy difundida por "Tomichio, Carbonello, Beutero, \& ceteris scriptoribus Hispanicis"37 (332-3).

También la idea de usurpación por parte de los condes de Barcelona, elaborado ya por Cassan, se encuentra presente en la mayoría de estos autores. Caseneuve (86-96) usa en repetidas ocasiones el concepto de usurpación para describir el gobierno de los condes de Barcelona quienes "ont usurpé la propieté"38 al "ne reconnoistre plus nos Roys, desquels comme i'ay fait voyr cydavant, ils estoient sujets \& Feudataires" ${ }^{39}$.

\footnotetext{
31 “Tradición fabulosa”.

32 "Son vasallos reconocidos de Nuestro Reino".

33 "Wifredo fabuloso"

34 "ninguna verdad".

35 "a favor de Wifredo".

36 "fabula segura".

37 "Tomic, Carbonell, Beuter y otros escritores españoles".

38 "han usurpado la propiedad".

39 "dejar de reconocer nuestros reyes, a los que estaban sujetos y de los que eran feudatarios, como he demostrado antes".
} 
Mesplède (38), por su parte, señala, igual que Cassan, el caso concreto de Alfonso II de Aragón como el primero en "haec autem Regum nostrum iura primus violare" ${ }^{30}$. La soberanía previa con Vuifredo también es descartada como una "donationem falsam" 41 , si bien admite que fue conde, pero como feudatario del rey franco (Mesplède 43-50).

La inalienabilidad de los derechos dinásticos de los reyes de Francia, también es abordada especialmente a partir del tratado de 1258 entre los reyes de Francia y Aragón. Caseneuve refiere dos motivos principales por los cuales el tratado debe ser considerado nulo. El primero está relacionado con las tierras del Languedoc que el rey de Aragón le cedió a la corona francesa a cambio de la soberanía sobre Cataluña. El autor señala que su padre Pedro II de Aragón había sido excomulgado por el papa en 1213 por haber protegido a herejes albigenses, hechos que llevarían a la conocida batalla de Muret aquel mismo año y en la cual el rey aragonés falleció. Ahora bien, señala Caseneuve que por la excomulgación el rey de Aragón habría perdido sus derechos sobre estas tierras. Concluye, por lo tanto, que "si Iaques d'Aragon, ne pouvoit pas donner ce qui n'etoit plus luy, S. Louys [Luis IX de Francia] ne pouvoit pas aussi aliener la Souveraineté d'un Pays qui faisoit depuis environ quatre cens ans une partie de la Coronne de France”"42 (124). El segundo motivo es precisamente la inalienabilidad que en cualquier caso impediría renunciar a la soberanía de una parte de su patrimonio por parte del rey de Francia. El monarca no tendría derecho de renunciar a ello, "ny tout, ny en partie" ${ }^{43}$, ya que "les oblige par la vertu des Loix fundamentales de a transmettre toute entiere à leurs Succeseurs" ${ }^{44}$ (Caseneuve 125-126).

Mesplède, en cambio, no hace referencias claras a la inalienabilidad, sin embargo, considera nulo el tratado de 1258. Coincide con Caseneuve en

\footnotetext{
40 "violar primero el derecho de nuestro reino".

41 "falsa donación".

42 "si Jaime de Aragón no podía entregar lo que no era más de él, S. Luis [XII de Francia] no podía alienar la soberanía de un país que desde hacía cuatrocientos ańos era parte de la corona de Francia".

43 "ni a todo, ni a una parte".

44 "estaba obligado por la virtud de las leyes fundamentales de transmitir todo entero a sus sucesores".
} 
que los territorios supuestamente cedidos por el rey de Aragón ya se habían perdido en el contexto de la batalla de Muret en el reinado de su padre (89). Sorel, en cambio, no se enfoca en acontecimientos particulares de manera muy concreta, sino que establece para todos los casos la inalienabilidad del patrimonio del rey de Francia, sean cuales sean las circunstancias. Incluso en caso de renunciar a una sujeción de una provincia por parte de un rey en particular, el derecho general "que nos Roys y avoient acquis, ne se peut perdre, quoy que luy \& ses succeseurs ayent cesse la reonnaissance" ${ }^{45}$, por lo cual "il est bien clair que la dépendance duroit tousiours" ${ }^{46}$ (Sorel 110). Más adelante, el autor reafirma que se trata de "son droict imprescriptible [del rey] y devoit etre conservé”77 (116).

En la parte final de su tratado, Sorel hace confluir la elección catalana de Luis XIII como conde de Barcelona con los derechos dinásticos de la corona francesa sobre el principado: "Ils ont choisi pour Roy celuy qui le devoit estre veritablement, \& que l'on peut dire n'estre pas leur Roy en verru de leur ellection, mais par son propre droict" ${ }^{\$ 8}$. Y cerrando su obra insiste que "ils ont reconnû qu'ils devoient plus obeyr à autre Monarchie qu’à celle de France, \& que nostre Roy estoit leur Roy legitime” ${ }^{49}$ (Sorel $137-8$ y 169).

\section{Conclusión}

En primer lugar, podemos constatar que los tres discursos referidos en la introducción, la justificación de la revuelta catalana, la justificación del cambio dinástico de Felipe IV a Luis XIII de Francia y la reivindicación de unos

\footnotetext{
45 "lo que nuestros reyes han adquirido no se puede perder, aunque él y sus sucesores hayan dejado de reconocerlo".

46 "está muy claro que la dependencia dura para siempre".

47 "su [del rey] derecho imprescriptible y debe ser conservado".

48 "Ellos han elegido como rey el que realmente debía serlo y que se puede decir que no es su rey por su elección, sino por su derecho propio".

49 "ellos han reconocido que a la única Monarquía a la que deben obedecer es la de Francia y que nuestro Rey es su Rey legítimo”.
} 
derechos de soberanía histórica de la corona francesa sobre el principado de Cataluña están presentes en la publicística francesa de la década de 1640 . Sin embargo, es preciso matizar que la presencia de los tres discursos es bastante desigual. Las justificaciones de la revuelta se presentan al lector francés principalmente a través de traducciones de obras catalanas, a las que se suma el texto de Charles Sorel y algún fragmento del Mercure Françoise. El discurso sobre el cambio dinástico tiene poca presencia en general y se encuentra principalmente en Sorel, único autor que incluye los tres en su obra. Finalmente, los derechos históricos de la corona francesa sobre Cataluña son revindicados por diversos autores franceses. Lo anterior evidencia que, si bien la publicística francesa estaba interesada en divulgar cualquier crítica o mala imagen de la monarquía hispánica, el verdadero interés consistía en destacar que el cambio dinástico se justifica sobre la base de los antiguos derechos de los reyes franceses en vez de las constituciones catalanas.

En segundo lugar, se puede detectar una evolución en la preponderancia de los distintos discursos. De los escritos analizados en este estudio, la justificación de la revuelta se presenta principalmente en los años 1641 y 1642, es decir, en los años posteriores a la rebelión. La justificación del cambio dinástico efectuado por los catalanes está menos presente que los otros discursos y su exponente principal es Charles Sorel (1642), el autor quien coincide en el primero y el segundo discursos de esta investigación, e incluso el tercero al final de su obra. Por último, el tercer discurso aparece principalmente desde 1644 en distintos manuscritos.

De lo anterior sería posible concluir que nos encontramos ante una evolución del discurso público francés que se adapta a los acontecimientos de la revuelta y de la guerra hispano-francesa en general. Sin embargo, creemos que esta interpretación sería demasiado simple, ya que obviaría algunas variables. Así, entre las justificaciones de la revuelta hay varias traducciones de obras catalanas, sobre todo de Gaspar Sala. En estos casos, los originales se insertan en un discurso que justifica la revuelta, pero es fiel a Felipe IV, publicándose durante la segunda mitad del año 1640. Las traducciones francesas, sin embargo, se publican cuando el discurso fidelista está obsoleto, es decir, tras el cambio dinástico en enero del 1641. Sin embargo, en las 
traducciones el texto no se altera ni se omite este componente fidelista a la dinastía Habsburgo. Interpretamos este hecho en el sentido de que creemos que la publicación y distribución de las acusaciones que justifican la revuelta tienen mayor peso y dejan en un segundo plano la reproducción de una fidelidad al monarca enemigo que en la práctica, ya no existía. Mantener, por lo tanto, el componente fidelista a Felipe IV constituye un mal menor para los traductores franceses, con tal de publicar fielmente las acusaciones graves que justificaban la revuelta del principado catalán.

La poca presencia en los textos franceses de justificaciones del cambio dinástico realizado por los catalanes hacia el monarca francés la explicamos por dos motivos. El primero es la continuidad del argumento previo que al parecer no tenía mucha relevancia para la publicística francesa, al prevalecer otros puntos como la exposición de tiranía de los soldados de Felipe IV y de la propia monarquía espańola. El segundo motivo creemos hallarlo justamente en el tercer discurso que justifica unos derechos históricos de la corona francesa sobre Cataluña. Estos derechos harían innecesario y posiblemente hasta incómodo para los autores franceses el hecho de que se produjera por elección de los catalanes, legitimación que anularía un derecho dinástico histórico y que reduciría el poder de la corona francesa en el principado.

Si bien dicho discurso aparece solo en 1644, en realidad se trababa de un discurso presente en décadas previas. Además, este apareció para reivindicar derechos sobre Cataluña y también sobre otros territorios de Europa. Entonces, la supuesta posesión del principado por la corona francesa es originalmente parte de un discurso mucho más extenso y que se individualizó en la década de 1640 para reforzar una situación política concreta basada en el hecho de que Luis XIII y después su hijo Luis XIV fueran condes de Barcelona y se pretendía presentar una legitimidad sobre Cataluña. 


\section{Bibliografía}

Anónimo. Appuy de la verite catalane, Ruan: Jean Berthelin, 1642.

Arredondo, María Soledad. Literatura y propaganda en tiempo de Quevedo: guerras y plumas contra Francia, Cataluña y Portugal. Madrid: Iberoamericana, 2011.

Aznar, Daniel. Cataluña y el rey. Representaciones y prácticas de la majestad durante el cambio de soberania (1640-1655). Tesis doctoral, Universidad de Barcelona, 2016.

_. $\quad$ "La Catalunya borbònica (1641-1659): Virregnat i dinàmiques de poder durant el govern de Lluís XIII i Lluís XIV de França al Principat". Del Tractat del Pirineus [1659] a l'Europa del segle XXI: un model en construcció. Editado por Óscar Jané. Barcelona: Generalitat de Catalunya, 2010, pp. 269-78.

_. "LLlorar de amor la pérdida de un rey? El cambio de fidelidad de los catalanes en 1641". Decidir la lealtad. Leales y desleales en contexto (siglos XVI-XVII). Editado por Alicia Esteban Estríngana. Madrid: Ediciones Doce Calles, 2017, pp. 281-314.

Bechade, Hervé. Les roman comiques de Charles Sorel: fiction narrative, lange et langages. Ginebra: Droz, 1981.

Belenguer, Ernest. Cataluña: de la unión de coronas a la unión de armas (1479-1626). Madrid: Arco Libros, 1996.

Caseneuve, Pierre. La Catalogne Françoise. Tolosa: Pierre Bosc, 1644.

Cassan, Jaques de. La recherche des droit du roy, \& de la couronne de France, sur les royaumes, duchez, comtez, villes \& pais occupez par les Princes estrangers. París: Nicolas Trabouillet, 1634.

Catford, John. A Linguistic Theory of Translation. Londres: Oxford UP, 1965.

Chamorro Esteban, Alfredo. Barcelona y el rey. Las visitas reales de Fernando el Católico a Felipe V. Barcelona: Ediciones La Tempestad, 2017.

Dickmann, Fritz. "Rechtsgedanke und Machtpolitik bei Richelieu: Studien an neu entdeckten Quellen". Historische Zeitschrift, n. ${ }^{\circ}$ 196, 1963, pp. 265-319.

Dupuy, Pierre y Théodore Godefroy. Traitez touchant les droits du Roy tres chrestien sur plusieurs estats et seigneuries possedées par diverses princes voisins. París: Augustin Courbé, 1655. 
Elliott, John H. The Revolt of the Catalans. A Study in the Decline of Spain, 15981640, Cambridge: Cambridge UP, 1984 [1963].

Farr Church, William. Richelieu and Reason of State. Princeton: Princeton UP, 2015 [1972].

Gloël, Matthias y Pilar Vivar. "La defensa de la lengua propia en un contexto de diglosia literaria en Cataluña, Portugal y el Reino de Valencia en los siglos XVI y XVII". Boletín de Filología, vol. 55, n. ${ }^{\circ}$ 1, 2020, pp. 273-96.

Hanley, Sarah. The Lit de Justice of the Kings of France. Constitutional Ideology in legend, ritual and discourse. Princeton: Princeton UP, 2014 [1983].

Lesens, Emile. "Imprimeurs et libraires rouennais et dieppois, protestant: avant 1789". Bulletin historique et littéraire (Société de l'Histoire du Protestantisme Français), vol. 36, n. ${ }^{\circ}$ 6, 1887, pp. 331-36.

Marca, Pierre de. Marca Hispanica sive limes hispanicus. París: François Muguet, 1688.

Martí i Viladamor, Francesc. Cataluña en Francia, Castilla sin Cataluña y Francia contra Castilla. Barcelona: Lorenço Deu, 1643

Mercure Françoise, tomo XXIII. París: Olivier de Varennes, 1646.

Mercure Françoise, tomo XXIV. París: Olivier de Varennes, 1647.

Mesplède, Louis. Catalania Galliae Vindicata. París, 1644.

Neumann, Karsten. "La justificación 'ante el mundo'. Difusión y recepción de la propaganda catalana en Europa en 1640". Pedralbes, vol. 18, n. ${ }^{\circ} 2,1998$, pp. 373-81.

Nida, Eugene. Toward a Science of Translating. Leiden: Brill, 1964.

Pelayo, Javier Antón y Montse Jiménez Sureda. "Francisco Martí i Viladamor: un pro-francés durante la Guerra dels Segadors". Manuscrits: Revista d'Història Moderna, n. ${ }^{\circ}$ 9, 1991, pp. 289-304.

Peña Díaz, Manuel. "El castellano en la Cataluña de los siglos XVI y XVII". Manuscrits: Revista d'Història Moderna, n. ${ }^{\circ}$ 15, 1997, pp. 149-55.

Pérez Latre, Miquel. Entre el rei i la terra. El poder polític a Catalunya al segle XVI. Vic: Eumo Editorial, 2003.

Roux, Olivier. Charles Sorel: la figure, la ligne et l'invention de l'auteur. París: Champion, 2014. 
Sala, Gaspar. Plainte Catholique des Catalans. Ruan: Jean Berthelin, 1641.

_. $\quad$ Secrets Publiques de la Catalogne. Ruan: Jean Berthelin, 1642.

Serra, Eva. Escrits politics del segle XVII / T. 2; Secrets públics de Gaspar Sala, i altres textos. Vic: Eumo, 1995.

Serrano Daura, Josep. "La donación de Ramiro II de Aragón a Ramón Berenguer IV de Barcelona, de 1137, y la institución de casamiento en casa”. Hidalguía, n. 270,1998 , pp. 709-19.

_. El Principado de Cataluña”. Hidalguía, n. ${ }^{\circ}$ 282, 2000, pp. 929-35.

Simon i Tarrés, Antoni. Construccions politiques $i$ identitats nacionals. Catalunya $i$ els origens de l'estat modern espanyol. Barcelona: Publicacions de l'Abadia de Montserrat, 2005.

_. Els origens ideològics de la revolució catalana de 1640. Barcelona: Publicacions de l'Abadia de Montserrat, 1999.

Sorel, Charles. La deffence des Catalans. París: Nicolas de Sercy, 1642.

Syrovy, Daniel. Tilting and tradition. Problems of genre in the novels of Miguel de Cervantes and Charles Sorel. Ámsterdam: Rodopi, 2013.

Terrón Vasco, Carlos. "La visión de Francia Durante la guerra de los Segadors a través de sermones catalanes”. Pedralbes, vol. 18, n. ${ }^{\circ}$ 2, 1998, pp. 383-89.

Torres Sans, Xavier. Naciones sin nacionalismo. Cataluña en la monarquía hispánica (siglos XVI-XVII). Valencia: Universitat de València, 2008.

Villanueva, Jesús. "Intentos franceses de legitimación de la anexión de Cataluña tras la revuelta de 1640: de Richelieu a Mazarino’. Pedralbes, n 18(2), 1998, pp. $135-144$.

- $\quad$ "La Marca Hispanica de Pierre de Marca y Étienne Baluze a través de sus tres momentos de composición $(1648,1660,1688)$ : de 'ilustración’ humanista a colección documental”. Pedralbes, n² 24, 2004, pp. 205-32.

- Politica y discurso histórico en la España del siglo XVII. Las polémicas sobre los orígenes medievales de Cataluña. Alicante: Publicaciones de la Universidad de Alicante, 2004. 